\title{
Noninvasive Respiratory Support in Infants and Children
}

\author{
Katherine L Fedor MBA RRT-NPS CPFT
}

\author{
Introduction \\ Indications \\ Asthma \\ Bronchiolitis \\ Pediatric ARDS \\ Cystic Fibrosis \\ Obstructive Sleep Apnea \\ Neuromuscular Disorders \\ Cardiac Disease \\ Predictors of Success \\ Contraindications \\ Interfaces \\ Delivery Devices \\ Challenges \\ Noninvasive Ventilation-Neurally Adjusted Ventilatory Assist \\ Sedation \\ Adherence \\ Measurements and Monitoring \\ Clinical Management \\ CPAP \\ Noninvasive Ventilation \\ Alternative Approaches to Noninvasive Modalities \\ Safety and Complications \\ Summary
}

\begin{abstract}
CPAP and noninvasive ventilation (NIV) offer an alternative to intubation and mechanical ventilation in the treatment of acute and chronic respiratory disorders commonly encountered in infants and children. There are many distinct challenges associated with the application, management, and safety of CPAP and NIV in the pediatric population. This review attempts to identify indications, contraindications, management strategies, and safety measures associated with the application of CPAP or NIV delivery in children. More recently, high-flow nasal cannula (HFNC) has emerged as an alternative to CPAP and NIV. Evidence related to the use of CPAP, NIV, and HFNC is included in this review. Key words: noninvasive ventilation; high-flow nasal cannula; continuous positive airway pressure; respiratory distress syndrome; pediatrics. [Respir Care 2017;62(6):699-717. (C) 2017 Daedalus Enterprises]
\end{abstract}

\section{Introduction}

Noninvasive respiratory support is used in infants and children with acute and chronic conditions associated with impaired respiratory drive, inadequate lung inflation, and altered gas exchange resulting in respiratory insufficiency or failure. Previously, a predominance of the evidence was devoted to the neonatal and adult population, but recent evidence advocating for less invasive ventilation has been a catalyst to increase the study and use of CPAP or noninvasive ventilation (NIV) in infants and pediatric patients. CPAP refers to the administration of continuous positive airway pressure during all phases of the respiratory cycle of a spontaneously breathing patient, whereas NIV refers to the application of 2 pressure levels (inspiratory and expiratory) designed to enhance ventilation by creating 


\section{Noninvasive Respiratory SupPort In INFANTS AND ChILDREN}

pressure gradients that facilitate the movement of air in and out of the lungs. Both CPAP and NIV have a goal that is consistent with improving or adequately restoring the functional residual capacity in the lung while minimizing the inspiratory work of breathing. The primary goal for the use of CPAP is to improve oxygenation by improving functional residual capacity and lung inflation in patients with an adequate respiratory drive. NIV improves the effective minute ventilation enhancing $\mathrm{CO}_{2}$ elimination by augmenting inspiration in patients with respiratory failure or impending respiratory failure without the use of an artificial airway. Effective ventilation will also result in improved oxygenation as the ventilation/perfusion ratio improves. NIV is commonly provided in the form of positive pressure; however, negative pressure delivery devices are available but are not widely used in the United States.

CPAP was first utilized in the neonatal population to treat respiratory distress syndrome associated with prematurity in the early 1970s. CPAP is administered by nasal prongs or mask to provide an adequate distending pressure that subsequently results in expansion and stabilization of collapsed alveoli secondary to surfactant deficiency. ${ }^{1-4}$ The successes seen in neonatal and adult CPAP and NIV use over the years have generated an expanded interest for its use in pediatric patient populations. The recent popularity and widespread use of high-flow nasal cannula (HFNC) have led to its inclusion in this discussion, although HFNC therapy should not be considered as a form of positive pressure delivery. Restoring or improving the functional residual capacity by applying continuous positive pressure to the ventilating lung units reduces the work of breathing by eliminating the need to overcome the opening pressure of the lung, and it prevents collapse and reopening of alveoli. CPAP does not provide tidal breathing support, and patients receiving CPAP alone must be able to maintain airway patency and have adequate respiratory muscle strength and neurological drive to breathe. With CPAP and NIV, care must be taken to avoid regional over distention of the lungs. Reducing the need for an artificial airway is the primary advantage for the use of noninvasive modal-

Ms Fedor is affiliated with Pediatric Respiratory Therapy, Cleveland Clinic, Cleveland, Ohio.

Ms Fedor discloses no conflicts of interest.

Ms Fedor presented a version of this paper at the 55th RESPIRATORY CARE Journal Conference, "Pediatric Respiratory Care," held June 10-11, 2016, in St Petersburg, Florida.

Correspondence: Katherine L Fedor MBA RRT-NPS CPFT, Pediatric Respiratory Therapy, Cleveland Clinic, 11100 Euclid Avenue, Cleveland, OH 44106. E-mail: fedork@ccf.org.

DOI: $10.4187 /$ respcare. 05244 ities, whereas secondary advantages include the reduced risk of nosocomial infections, decreased need for sedation, increased tolerance for enteral feeds, potential for care outside of the ICU, and an improved ability to ambulate.

\section{Indications}

The goals of therapy and the physiological effects will determine the indications for use of the various noninvasive modalities. Common indications for the use of CPAP, NIV, or HFNC (collectively referred to as noninvasive respiratory support) for specific patient populations are outlined in Table 1.1-4 The most common use of CPAP is seen in patients with hypoxemia related to alveolar collapse or symptoms associated with obstructive sleep apnea or upper-airway collapse. The majority of NIV in pediatric patients is utilized for the treatment of impending respiratory failure associated with acute or chronic respiratory insufficiency secondary to pulmonary disease, neuromuscular disease, airway obstruction, infectious processes, or postextubation management or to avoid intubation or reintubation. NIV can be effective in treating disorders related to hypercarbia and/or hypoxia and may be administered as an intermittent or continuous intervention based on patient need and reversibility of the indication. Pediatric studies on the use of noninvasive modalities suggest that proper patient selection can have a significant impact on outcomes.

\section{Asthma}

In subjects with asthma, Basnet et $\mathrm{al}^{5}$ performed a pilot study to evaluate the safety, efficacy, and tolerability of early initiation of noninvasive positive-pressure ventilation in pediatric patients admitted with status asthmaticus. This was a small homogeneous study of 20 subjects that compared early initiation of NIV plus standard care (shortacting $\beta$ agonists and systemic steroids) with standard care alone. Subjects received NIV by mask, the inspiratory positive airway pressure (IPAP) setting was titrated to $8 \mathrm{~cm} \mathrm{H}_{2} \mathrm{O}$ to achieve a tidal volume of $6-9 \mathrm{~mL} / \mathrm{kg}$, the expiratory positive airway pressure (EPAP) was set to $5 \mathrm{~cm} \mathrm{H}_{2} \mathrm{O}$, and supplemental oxygen was administered to achieve a saturation of $>92 \%$. Assessments were made at baseline, $0-2 \mathrm{~h}, 4-8 \mathrm{~h}, 12-16 \mathrm{~h}$, and $24 \mathrm{~h}$. The clinical asthma scores evaluated breathing frequency, accessory muscle use, air exchange, wheeze, and inhalation/exhalation ratios. The scores for the NIV group and the standard group indicated no differences in the severity of illness; however, the scores for the NIV group showed a more rapid decline in symptoms than for the standard treatment group at all intervals of assessment.

The use of NIV in asthma exacerbation has been shown to impact the use of mechanical ventilation, hospital stay, 


\section{Noninvasive Respiratory Support in INFANTS AND ChildRen}

Table 1. Indications for Noninvasive Respiratory Support in Infants and Children

\begin{tabular}{|c|c|}
\hline Indications & Modality \\
\hline \multicolumn{2}{|l|}{ Infants } \\
\hline Delivery-room management & $\mathrm{CPAP}^{*}$ or $\mathrm{NIV} \dagger$ \\
\hline Alveolar recruitment & $\mathrm{CPAP}^{*}$ or NIV $\dagger$ \\
\hline Post-extubation & $\mathrm{CPAP}^{*}, \mathrm{NIV} \dagger$, or HFNC* \\
\hline Hypotonia with respiratory insufficiency and depression & $\mathrm{CPAP}^{*}$ or $\mathrm{NIV} \dagger$ \\
\hline Conditions associated with loss of lung volume & $\mathrm{CPAP}$ or NIV $\dagger$ \\
\hline Obstructive airways diseases (tracheal malesia, bronchial malesia, laryngomalesia) & CPAP* \\
\hline \multicolumn{2}{|l|}{ Children } \\
\hline Respiratory insufficiency associated with acute lung injury & $\mathrm{CPAP}^{*}, \mathrm{NIV} \dagger$, or $\mathrm{HFNC}^{*}$ \\
\hline Pneumonia & $\mathrm{CPAP}^{*}, \mathrm{NIV} \dagger$, or $\mathrm{HFNC}^{*}$ \\
\hline Asthma & $\mathrm{CPAP}^{*}, \mathrm{NIV} \dagger$, or $\mathrm{HFNC}^{*}$ \\
\hline Bronchiolitis & $\mathrm{CPAP}^{*}, \mathrm{NIV} \dagger$, or $\mathrm{HFNC}^{*}$ \\
\hline $\begin{array}{l}\text { Pulmonary edema often associated with renal failure or cardiac failure associated with myopathy or } \\
\text { congenital heart disease }\end{array}$ & $\mathrm{CPAP}^{*}$ or $\mathrm{NIV}^{\dagger}$ \\
\hline Congenital heart disease is associated with increased work of breathing and pending respiratory failure & $\mathrm{CPAP}^{*}, \mathrm{NIV} \dagger$, or HFNC* \\
\hline Respiratory insufficiency associated with chronic lung disease & $\mathrm{CPAP}^{*}$ or $\mathrm{NIV} \dagger$ \\
\hline Cystic fibrosis & $\mathrm{CPAP}^{*}$ or NIV $\dagger$ \\
\hline Neuromuscular diseases & $\mathrm{CPAP}^{*}$ or $\mathrm{NIV} \dagger$ \\
\hline Neurologic disorders associated with respiratory depression & $\mathrm{CPAP}^{*}$ or NIV $\dagger$ \\
\hline Chest-wall deformities (scoliosis) & $\mathrm{CPAP}^{*}$ or $\mathrm{NIV} \dagger$ \\
\hline Post-extubation & $\mathrm{CPAP}^{*}, \mathrm{NIV} \dagger$, or $\mathrm{HFNC}^{*}$ \\
\hline Obstructive airway diseases (OSA, tracheal malesia, bronchial malesia, laryngomalesia) & $\mathrm{CPAP}^{*}, \mathrm{NIV} \dagger$, or $\mathrm{HFNC}^{*}$ \\
\hline \multicolumn{2}{|l|}{$\begin{array}{l}\text { Data from References } 4-6 \text {. } \\
* \text { Must have adequate respiratory drive to sustain adequate gas exchange. } \\
\dagger \text { Indicated when respiratory drive is insufficient to provide adequate gas exchange. } \\
\text { NIV = noninvasive ventilation } \\
\text { HFNC = high-frequency nasal cannula } \\
\text { OSA = obstructive sleep apnea }\end{array}$} \\
\hline
\end{tabular}

mortality rates, and patient costs. Miguel-Díez et al ${ }^{6}$ studied children admitted with asthma exacerbation over an 8 -y period from 2002 to 2010 . This study included $>12,000$ pediatric subjects, and findings related to the use of NIV included a decrease in hospital admissions of 1.8/100 pediatric subjects and a decrease in the mean length of stay (LOS) of $0.77 \mathrm{~d}$. The presumed decrease in patient costs is attributed to the decreased LOS. During the study period, the use of NIV increased from $0.91 \%$ of hospitalized subjects in 2002 to $3.30 \%$ of the subjects in 2009 , whereas a small decrease occurred in 2010.

\section{Bronchiolitis}

The use of NIV continues to gain popularity in bronchiolitis patients. A study by Ganu et al ${ }^{7}$ evaluated the impact of intubation rates over the last decade related to the increasing use of NIV in infants with severe bronchiolitis. This study compared outcomes of 520 infants with severe bronchiolitis with a median age of 2.8 months. Key outcomes were the median LOS in the pediatric ICU of subjects who were successfully treated with NIV compared with those who failed NIV or were treated only with intubation and mechanical ventilation. The LOS for subjects successfully treated with NIV was $2.4 \mathrm{~d}$ compared with $5.2 \mathrm{~d}$ for those who were intubated and mechanically ventilated and $8.4 \mathrm{~d}$ for subjects who failed NIV. Of the 520 infants, 121 received no positive pressure support, 237 received successful NIV, 114 were intubated and mechanically ventilated without a trial of NIV, and 48 failed NIV and required invasive mechanical ventilation. Over the 10 -y period, the use of NIV rose by $2.8 \% / y$, and invasive ventilation fell by $1.4 \% / y$.

In another study looking at acute respiratory failure due to bronchiolitis and pneumonia, Abadesso et $\mathrm{al}^{8}$ evaluated the effectiveness of NIV in avoiding endotracheal intubation and to assess risk factors associated with NIV failure. This study included infants with a mean age of $7.2 \pm 20.3$ months (102 subjects had bronchiolitis, 44 with pneumonia, 27 subjects with atelectasis, 20 with apnea, and 43 with upper-airway obstruction). Assessments were divided into success and failure groups. Both groups showed improvement in breathing frequency, heart rate, $\mathrm{pH}$, and $\mathrm{P}_{\mathrm{CO}_{2}}$ at 2, 6, 12, and $24 \mathrm{~h}$. However, the $\mathrm{S}_{\mathrm{pO}_{2}} / \mathrm{F}_{\mathrm{IO}_{2}}$ was sustained only in the NIV success group. The NIV failure group did have an improvement in $\mathrm{S}_{\mathrm{pO}_{2}} / \mathrm{F}_{\mathrm{IO}_{2}}$, but that im- 
provement was only present during the first $4 \mathrm{~h}$ following initiation of NIV. The overall failure rate in this study was $22.5 \%$, with the risk factors being identified as apnea, prematurity, pneumonia, and co-infections. The overall success rate was $77.5 \%$, with the remaining $22.5 \%$ requiring invasive mechanical ventilation. Subjects with pneumonia had the highest failure rate (26\%), followed by subjects with bacterial co-infections (17\%) and apnea (11\%). The highest degree of success was for subjects with bronchiolitis (95\%), whereas subjects with ARDS had zero success. Additionally, the LOS for the success group versus the failure group was $9.7 \pm 9.5 \mathrm{~d}$ versus $14.5 \pm 10.2 \mathrm{~d}$. The results of this study suggest that patients with bronchiolitis should be trialed with NIV before intubation.

There is some evidence that the use of a heliox (heliumoxygen) gas mixture during NIV may further increase the success of NIV in the treatment of bronchiolitis or other diseases associated with upper- or lower-airway obstruction. Martinon-Torres et $\mathrm{al}^{9}$ conducted a single-institution study evaluating subjects with bronchiolitis. Only 1 of 352 subjects $(0.28 \%)$ admitted to the pediatric ICU required intubation after being treated with heliox or heliox with NIV. Mixtures can be administered in helium/oxygen concentrations of $80 \% / 20 \%, 70 \% / 30 \%$, or $60 \% / 40 \%$, with the greatest benefit for the $80 / 20$ gas mixture. There are some commercially available ventilators that are designed to deliver helium-oxygen gas mixtures and therefore convert measurements to accommodate the density of the gas. However, caution must be taken if a clinician modifies a device to administer a helium-oxygen gas mixture that does not correct for the altered gas mixture. Flows will be higher when using a helium gas mixture with a flow meter calibrated for oxygen. Specifically, the flow through an oxygen-calibrated flow meter will be 2.1 times higher when using $80 \%$ helium, 1.7 times higher when using $70 \%$ helium, and 1.4 times higher when using 60\% helium.

\section{Pediatric ARDS}

In 2015, the Pediatric Acute Lung Injury Consensus Conference Group published recommendations on pediatric ARDS. ${ }^{10}$ A key recommendation was that NIV should be delivered in a setting with trained experienced staff that offers close monitoring of the patient (100\% agreement), it should be used early in the disease process to improve gas exchange and decrease the work of breathing to avoid invasive ventilation complications ( $88 \%$ agreement). This group concluded, with $80 \%$ agreement, that immunodeficient patients are at a greater risk of complications from invasive ventilation and may benefit from early intervention with NIV. They did not recommend NIV for children with severe disease and recommended intubation for patients who do not show clinical improvement or have signs of worsening disease (100\% agreement). When using NIV, the consensus group recommended using an oronasal or total face mask to maximize effective ventilation $(84 \%$ agreement) and strongly encouraged the use of heated humidification (100\% agreement). Patient comfort and safety issues were also addressed. There was strong agreement $(100 \%)$ on the monitoring of skin breakdown, gastric distention, barotrauma, and conjunctivitis. Sedation was recommended to improve patient ventilator synchronization and tolerance (88\% agreement). The use of pressure support or CPAP was recommended to achieve synchrony or when using a nasal mask interface ( $92 \%$ agreement).

\section{Cystic Fibrosis}

One of the most debilitating chronic pulmonary diseases in children is cystic fibrosis. Studies have shown that there are many benefits to the use of NIV to improve the activities of daily living in this patient population. Flight et $\mathrm{al}^{11}$ studied the rate of decline in lung function and the FEV measurements in 47 subjects with cystic fibrosis. Participants in this study had significant lung disease, with an average $\mathrm{FEV}_{1}$ of $0.83 \mathrm{~L}$ and an $\mathrm{FVC}$ of $1.76 \mathrm{~L}\left(\mathrm{FEV}_{1} / \mathrm{FVC}\right.$ of 0.47 ) before initiation of NIV. Results indicated that 24 of the 33 subjects who had baseline data before and after initiation of NIV showed an improvement in $\mathrm{FEV}_{1}$ or a reduction in the rate of decline. This study reported that NIV may improve lung function, prolong and improve the quality of life, and contribute to improved health status and better outcomes following lung transplantation.

The positive effects on exercise tolerance with the use of NIV on cystic fibrosis subjects is well supported. One study looked at the effects on the walk distance and chestwall volumes in subjects with cystic fibrosis. In a randomized crossover clinical trial, Lima et al ${ }^{12}$ evaluated 13 subjects with cystic fibrosis for walk distance and regional chest wall volumes with and without the use of NIV. All subjects were between 7 and 16 y old without evidence of respiratory failure within the previous 3 months and had an $\mathrm{FEV}_{1}$ of $<80 \%$ of predicted. Results indicated that the walk distance had increased by approximately $7 \%$ $(415.38 \pm 77.52 \mathrm{~m}$ vs $386.92 \pm 84.89 \mathrm{~m})$ and percentof-predicted $\mathrm{FEV}_{1}$ increased by approximately $9 \%(67 \%$ vs $61 \%$ ) with NIV. Fauroux ${ }^{13}$ suggested that pressure support should be provided in subjects with cystic fibrosis, citing improved patient comfort secondary to decreased muscle work and patient the ability of the patient to control the inspiratory and expiratory phase of ventilation.

\section{Obstructive Sleep Apnea}

The prevalence of obstructive sleep apnea (OSA) in children ranges from 1 to $10 \%$ and results in a number of consequences, including failure to thrive, attention-deficit 
disorder, behavioral problems, poor academic performance, and cardiopulmonary disease. ${ }^{14}$ OSA in children is defined as an apnea-hypopnea index of $>1$ and a minimum oxygen saturation of $<92 \%$ during polysomnography. Treatment of pediatric OSA may involve surgical removal or repair of the obstructive airway component or the use of nocturnal CPAP. The use of CPAP in these patients involves the application of positive pressure to maintain the patency of the airway during tidal breathing by creating a pneumatic stent preventing airway collapse through the airway cycle. Although CPAP is an effective treatment for OSA, it is challenging in children, with intolerance or failure to adhere occurring in $20 \%$ of subjects. All patients with suspected apnea should have a sleep study to determine the origin of apnea (central vs obstructive). CPAP is only indicated in the presence of OSA; patients with central sleep apnea should be evaluated for placement of a permanent artificial airway versus nocturnal NIV.

\section{Neuromuscular Disorders}

Another common indication for the use of NIV is seen in children with neuromuscular disorders. NIV may be used to treat acute respiratory failure or may be used as a primary intervention in the treatment of chronic hypoventilation. In a study conducted by Piastra et al, ${ }^{15} 10$ pediatric subjects with neuromuscular disease and acute respiratory failure were treated with NIV, with 8 of the subjects successfully avoiding intubation. Subjects who were successfully treated with NIV experienced an increase in mean $\mathrm{P}_{\mathrm{aO}_{2}} / \mathrm{F}_{\mathrm{IO}_{2}}$ from 75 (at the onset of NIV) to 240 and 328 at 3 and $12 \mathrm{~h}$ following the initiation of therapy, and acute respiratory failure was resolved within $6 \mathrm{~h}$. Clinical outcome at discharge showed that 3 subjects required tracheostomy with mechanical ventilation, 3 fully recovered without discharge intervention, 2 were discharged receiving NIV, and the 2 failure subjects died: one after 12 months and one after 24 months of hospitalization. This suggests that NIV can be routinely attempted in pediatric patients with neuromuscular disease to avoid or delay invasive ventilation with an artificial airway.

\section{Cardiac Disease}

In pediatric patients with heart disease, the overall success rate of NIV following extubation was found to be $77.8 \%$ when used prophylactically or when acute respiratory failure was noted. ${ }^{16}$ Participants were assigned to a prophylactic group or a non-prophylactic group; 201 subjects received CPAP, whereas 20 subjects received NIV. The prophylactic group had a shorter LOS in the ICU and in the hospital than the non-prophylactic group (median of $49 \mathrm{~d}$ vs $88 \mathrm{~d}$ in the ICU and median $60 \mathrm{~d}$ vs $103 \mathrm{~d}$ in the hospital). There were no differences in the LOS between responders and non-responders, and the ICU mortality rate was significantly higher in the non-responder group versus the responders ( $31 \%$ vs $4 \%$ ), but there was no difference in mortality between the prophylactic and non-prophylactic groups (both were noted at 10\%). These data suggest that the successful use of noninvasive modalities following extubation in children with cardiac disease can lower mortality rates, decrease the LOS in the ICU and the hospital, and reduce re-intubation rates.

\section{Predictors of Success}

The general success or failure of NIV is difficult to predict and is often attributed to the lack of availability of patient-specific interfaces or therapy intolerance. One study involving pediatric subjects with respiratory failure by Bernet et al ${ }^{17}$ suggests that the $\mathrm{F}_{\mathrm{IO}_{2}}$ level after $1 \mathrm{~h}$ of NIV may be a predictive factor for success. This study showed that in the first hour following initiation of NIV, non-responders had a median $\mathrm{F}_{\mathrm{IO}_{2}}$ requirement of 0.8 compared with 0.48 for responders.

\section{Contraindications}

Contraindications for the use of noninvasive modalities in infants and pediatric patients are shown in Table 2.3.18 Contraindications include medical conditions or treatment failures associated with respiratory failure or complications that occur as a direct result of the application of positive pressure. In addition to the clinical contraindications, patients may need to be removed from NIV secondary to serious complications associated with the patient interface device, such as skin ulcerations or deep-tissue injury. Although risk of aspiration is not an absolute contraindication for the use of noninvasive modalities, these patients do require additional precautions related to the delivery interface, feeding, and monitoring to reduce the incidence of aspiration.

\section{Interfaces}

With an increased interest and use of noninvasive treatment modalities in pediatric patients, manufacturers are increasing their selection of patient interfaces. Limitations associated with successful application and use of CPAP and/or NIV can be attributed to the patient interfaces, the delivery devices, and the available technology. Interfaces include nasal prongs, nasal pillows, nasal masks, oronasal masks, total face masks, and extended nasal prongs or nasal tubes positioned in the nasal pharyngeal airway. The primary patient interfaces used in small infants are nasal prongs and nasal masks. Both nasal prongs and nasal masks are associated with system leaks, which may necessitate 
Table 2. Contraindications for Noninvasive Respiratory Support

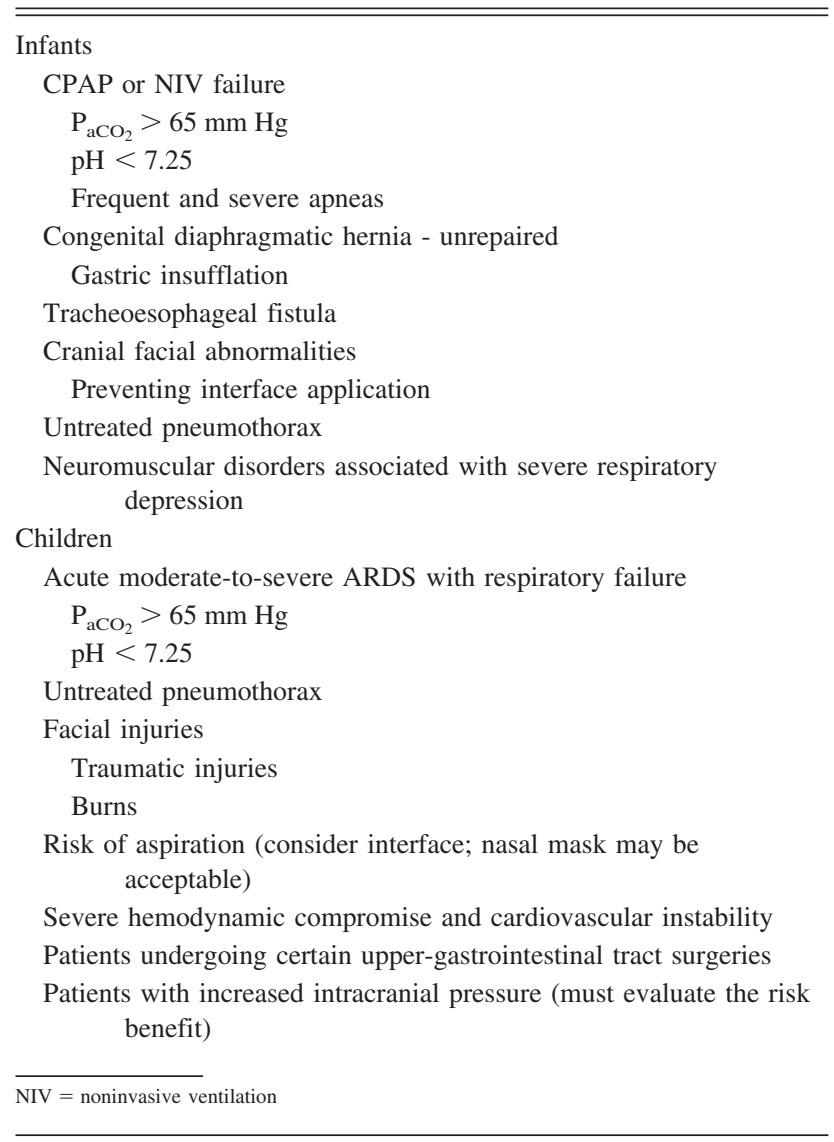

the use of a chin strap to maximize positive pressure delivery.

The recent popularity of the RAM cannula, which is not FDA-cleared for use as a CPAP or NIV delivery device, poses an added delivery challenge, since this is a non-occlusive nasal cannula interface, and performance will not be significantly impacted by the use of a chin strap. The presence of interface leaks on any device will negatively affect the triggering capabilities of the delivery device, an effect that is exaggerated by the infant's inability to generate measurable inspiratory flow through the system.

Pediatric interfaces are also impacted by design and leaks associated with application. Pediatric interfaces have recently expanded, but they still present challenges related to triggering, monitoring, and volume measuring. Leak compensation is a mechanism that can determine and quantify the presence of an interface leak and thus compensate for the triggering requirement needed to initiate an inspiratory effort during NIV, provided the leak is reasonably stable. If the leak is highly variable, compensation will also be variable and may result in asynchrony. If a substantial volume of gas is contained within a mask interface, the ability to effectively trigger breath delivery will be impacted which can still present a challenge in the pediatric patient. Impaired respiratory muscle strength will greatly affect the ability to trigger a breath even when the amount of gas contained within the interface is minimized and leak compensation is employed. Under these conditions, it may be necessary to utilize a spontaneous timed mode to ensure adequate breath delivery when NIV is indicated. Other factors to consider when selecting the patient interface will include patient headgear and patient safety risks related to the potential for the development of skin ulcerations, gastric insufflation, and aspiration. When the risk of aspiration is present, it is best to select a nasal mask if possible to minimize exposure to the accumulation of secretions and/or gastric contents and reduce the potential for suffocation. The risk of gastric insufflation can be reduced by placement of a vented nasogastric or oral gastric tube, whereas the risk of skin ulcerations can be reduced by alternating patient interface devices, adherence to careful skin care protocols, and the use of skin barriers. An abbreviated list of commonly used infant and pediatric interfaces is shown in Figure 1.

\section{Delivery Devices}

There are several stand-alone devices capable of delivering CPAP to infants weighing $<5-7 \mathrm{~kg}$ and pediatric patients $>20$ or $30 \mathrm{~kg}$. When NIV is required for patients weighing between 7 and $20 \mathrm{~kg}$ in the in-patient setting, delivery devices are typically limited to the use of universal ICU ventilators or portable home-care ventilators with NIV capabilities. When pediatric patients are discharged home receiving positive airway pressure, the choices are further limited to the home-care ventilators with noninvasive capabilities based on the existing FDA-cleared constraints.

\section{Challenges}

The biggest logistical limitations related to the application of NIV in infants and children are the interfaces and delivery devices. In recent years, the patient interfaces and headgear for pediatric patients has expanded greatly and includes a wider variety of total face masks, nasal masks, nasal pillows, and, most recently, cloth masks. Careful attention to the interface device connection is an important component of the circuit; some delivery systems require a vented circuit to allow for leak compensation and exhalation, whereas mechanical ventilators utilize the internal exhalation valve, and a closed circuit is required. Many of the interfaces have interchangeable system connections that allow for the exchange of vented and nonvented interface elbows. 


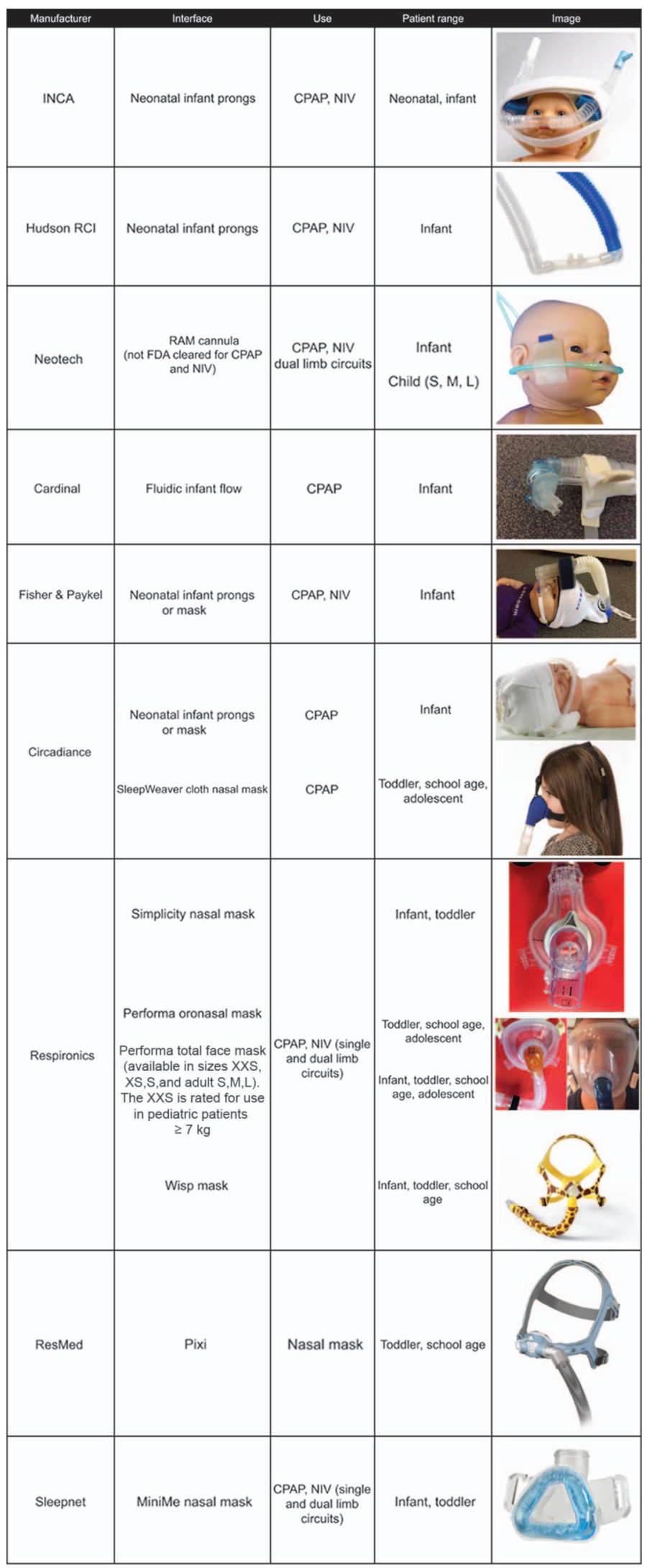

Fig. 1. Patient interfaces. Courtesy Respironics, Circadiance, Sleepnet, Neotech, ResMed, Teleflex, and CooperSurgical. 


\section{Noninvasive Respiratory SupPort In INFANTS AND ChILDREN}

Patient triggering presents a significant problem for the pediatric patient population. Challenges associated with triggering are often due to small tidal volumes, leaks related to the type of interface, the volume of gas contained within the interface, and poor respiratory muscle strength of the patient. Triggering capabilities improve as leaks are minimized and when total face masks are utilized. Other adjuncts, such as chin straps and nasal prong occluding devices, may help to reduce leaks and improve performance. Some devices offer auto-track triggering to accommodate variable leaks in the system, which will improve effective triggering, provided the delivery device can detect patient effort.

Mask interfaces are often associated with large residual volumes within the mask, making it difficult to generate enough flow within the circuit to trigger an inspiratory breath. The ability to trigger or not trigger will influence how NIV is managed and must be evaluated on a caseby-case basis. Many infants successfully receive unsynchronized NIV using a pressure-limited time-cycled strategy, whereas some clinicians attempt to synchronize patient interaction using pneumatic signals, such as flow or pressure. Even when using pneumatic signals to improve patient interaction, rapid breathing frequencies, small tidal volumes, and leaks can still present a challenge. To complicate matters, delivery is generally pressure-limited and does not accommodate variability in respiratory demand.

\section{NIV-Neurally Adjusted Ventilatory Assist}

Recent advances in technology have given clinicians other tools to enhance the effectiveness of NIV in all patients. One such tool is the emergence of neurally adjusted ventilatory assist (NAVA). In a review of NIV with NAVA in newborns by Stein et al, ${ }^{19}$ the importance of patient synchronization was evaluated. NAVA ventilation and the specially designed NAVA catheter are proprietary to the Servo ventilator (Maquet, Solna, Sweden). The NAVA catheter detects electrical signals received by the diaphragm and is reflective of neural respiratory drive. The diaphragm signals exist at 2 levels: the maximum diaphragm signal, which represents the inspiratory effort or work of the diaphragm, and the minimum diaphragm signal, which represents the expiratory effort required to prevent de-recruitment. When the diaphragm signal catheter is properly placed, signals are based on the muscle activity of the diaphragm. These signals not only provide excellent synchronization; they also accommodate variability in the infant's sporadic breathing patterns and are unaffected by system leaks.

Successful use of NIV-NAVA is limited by the functionality of the NAVA catheter and the neurologic respiratory drive of the patient. However, NAVA provides important backup safety features to address these occurrences. If a diaphragm electrical signal cannot be detected, the

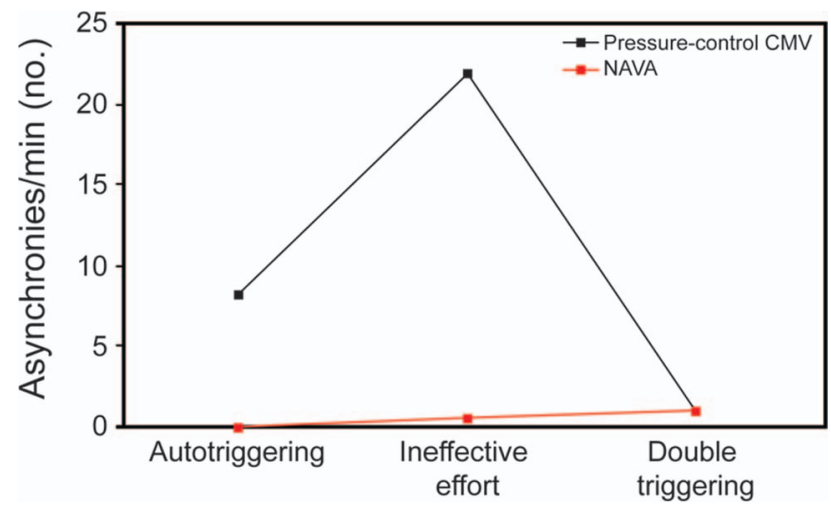

Fig. 2. Noninvasive ventilation asynchrony. Pressure-control continuous mandatory ventilation (CMV) vs neurally-adjusted ventilatory assist (NAVA). Data from Reference 20.

ventilator will provide backup noninvasive pressure control ventilation; however, this technology is not available for home use.

Baudin et $\mathrm{a}^{20}$ conducted a small crossover study of 11 subjects with bronchiolitis to evaluate asynchrony using noninvasive NAVA versus noninvasive pressure control. Asynchrony was assessed by the asynchrony index (the number of times auto-triggering and/or double triggering occurred per minute), and the numbers of ineffective patient breathing efforts were noted per minute. In this study, a NAVA catheter was placed before initiating pressure control, subjects were switched to NAVA after $2 \mathrm{~h}$, and factors related to patient synchrony were evaluated. When subjects were placed into NAVA, the NAVA level was titrated to a level that produced an equivalent peak pressure, PEEP remained stable, and the $\mathrm{F}_{\mathrm{IO}_{2}}$ was decreased to the lowest possible level in both modes. Significant differences between pressure control and NAVA were noted related to auto-triggering $(8.2 / \mathrm{min}$ vs $0.09 / \mathrm{min})$, ineffective efforts (21.8/min vs $0.54 / \mathrm{min})$ (Fig. 2), asynchrony index (38\% vs 3\%), and trigger delays (116.0 ms vs 43.9 $\mathrm{ms})$.These authors suggest that these data indicate that NAVA is associated with a significant improvement in patient-ventilator interactions. Additional studies should be done to evaluate the clinical impact of this improved patient-ventilator interaction on key outcomes measures. Additionally, more randomized controlled trials are needed to determine how to most effectively interpret and adjust mandatory settings. Figure 3 demonstrates the inability to trigger during NIV, Figure 4 demonstrates improved trigger capture with the use of NAVA, and Figure 5 demonstrates inadequate support with a high inspiratory work of breathing during NAVA. ${ }^{20}$

\section{Sedation}

The use of sedation to improve patient tolerance in patients receiving noninvasive ventilation should be given 


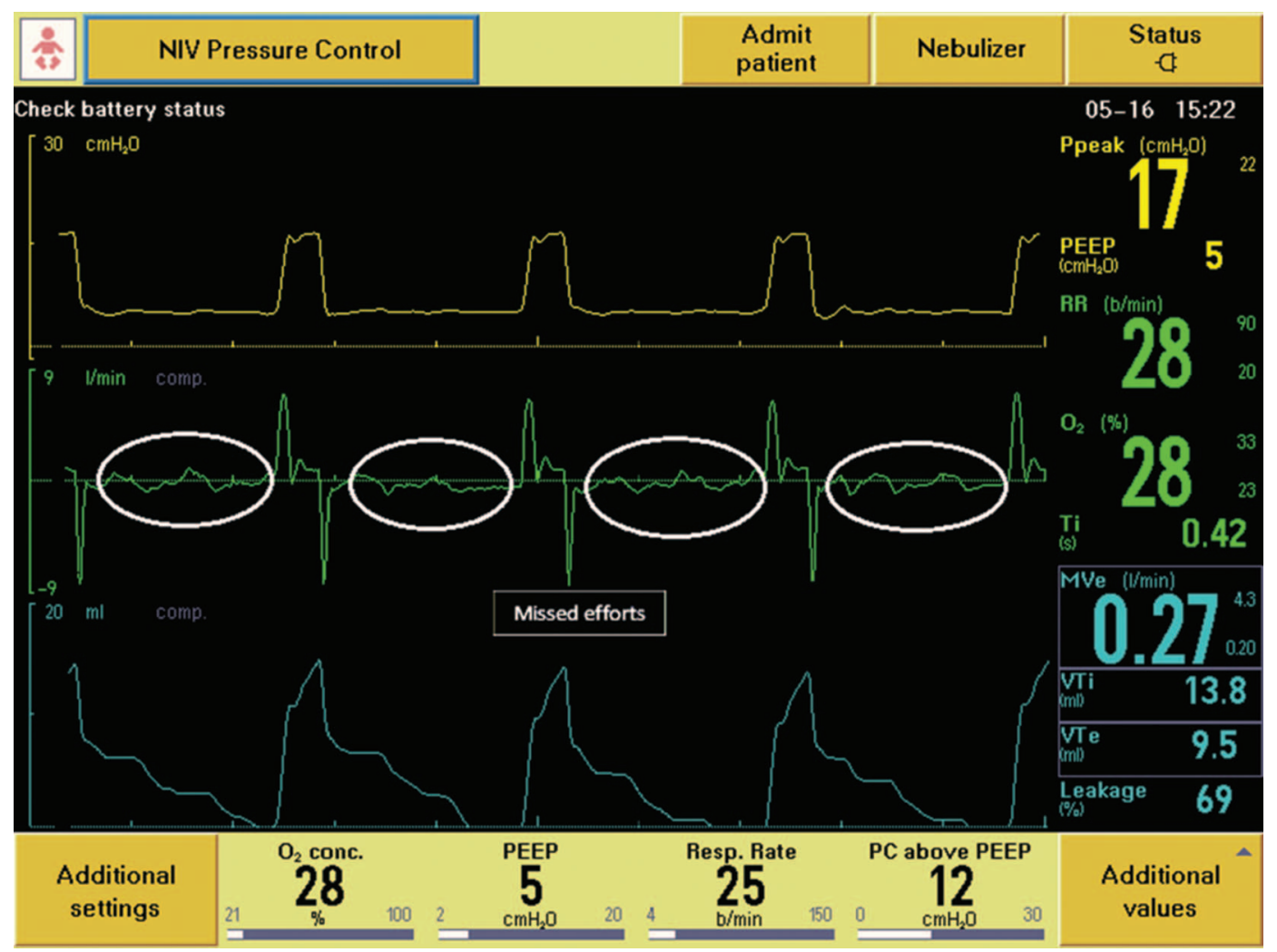

Fig. 3. Noninvasive ventilation unable to capture patient effort.

careful consideration. Patients may not tolerate application of the interface appliance or the excessive flow sometimes associated with NIV. If it is necessary to administer anti-anxiety medications to facilitate patient tolerance, it will be important to choose a pharmacologic agent, such as midazolam, that produces minimal respiratory depression.

\section{Adherence}

Adherence in pediatric subjects receiving CPAP was studied by Hawkins et $\mathrm{al}^{21}$ They found that overall adherence was $49 \%$ of the subjects evaluated (69 of 140). Adherence was defined as $>70 \%$ nightly use and average usage of $\geq 4 \mathrm{~h} /$ night. Specifically, they found that females had better adherence than males (60.9\% vs $39.5 \%)$, and children with developmental delays also had better adherence. Poor adherence could contribute to poor outcomes related to respiratory insufficiency and may lead providers to perform more invasive alternatives. Interface adherence may be enhanced by desensitization efforts and role-playing. This process may require creative thinking by the practitioner and assistance from the family or child life department, which may be helpful in distracting the patient.

\section{Measurements and Monitoring}

Accuracy in volume delivery is difficult to achieve during NIV. System leaks are the biggest factor in volume measurements, but the size of the interface and the amount of residual volume within the interface also contribute to the volume measurement. Delivered tidal volume is a direct reflection of the difference between IPAP and EPAP during NIV, but due to inaccuracies in measurements, other clinical indicators should be used in the management of NIV. This issue is less concerning for patients only receiving CPAP therapy. Clinical indicators of adequate tidal volume during NIV will include assessment of chest rise, breath sounds, noninvasive forms of $\mathrm{O}_{2}$ and $\mathrm{CO}_{2}$ monitoring, and the level of consciousness. Ultimately, adequate evaluation of ventilation may require blood gas analysis.

Monitoring of patients receiving CPAP or NIV should include pulse oximetry with saturation targets specific for the patient based on diagnosis and acuity of the disease process. Pulse oximetry is a good indicator of oxygenation status; however, it is of little value related to the ventilation status of the patient. The adequacy of ventilation must include some periodic form of $\mathrm{CO}_{2}$ measurement. $\mathrm{CO}_{2}$ measurements can be obtained noninvasively with trans- 


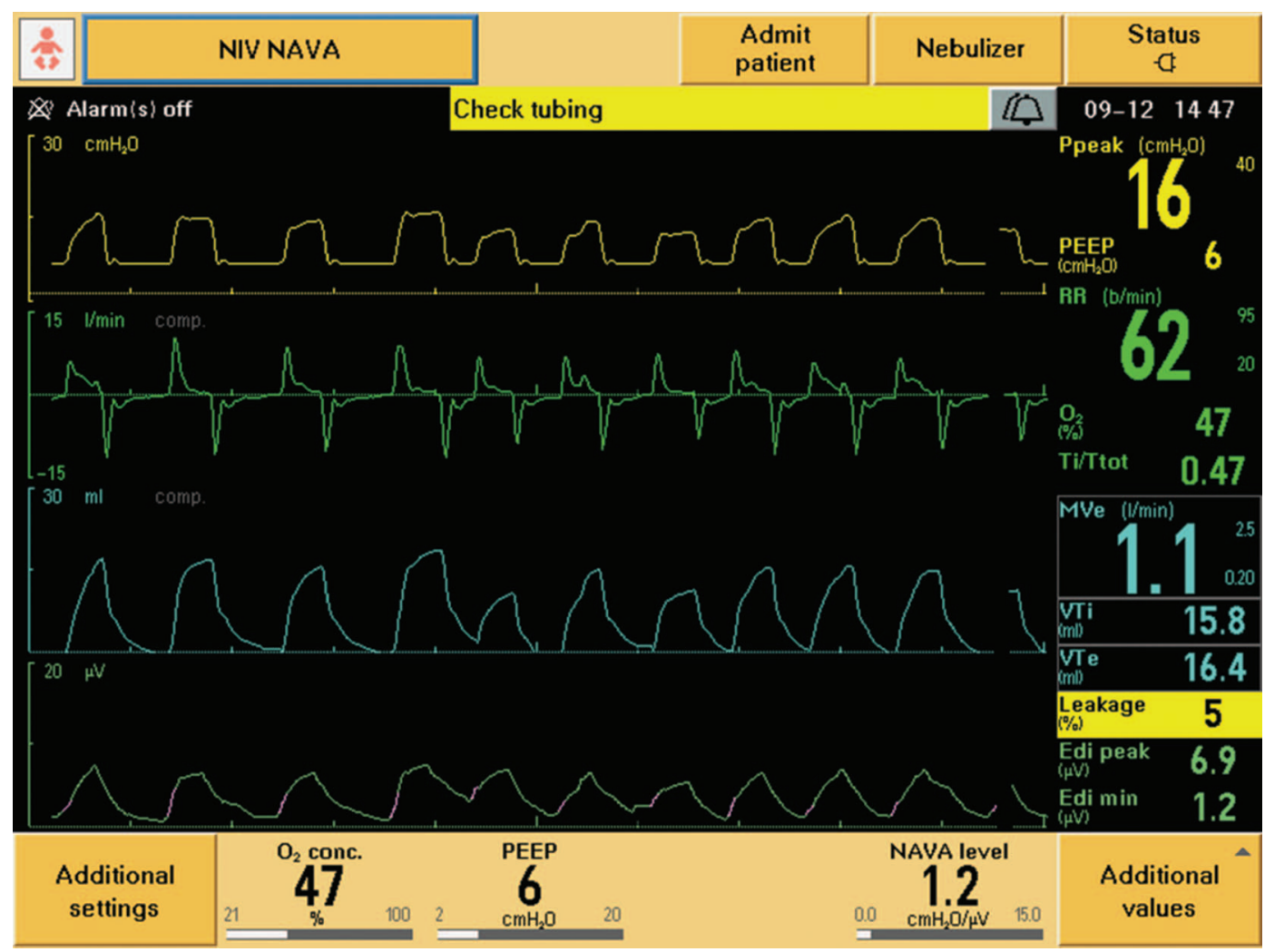

Fig. 4. Noninvasive ventilation-neurally adjusted ventilatory assist (NIV-NAVA) where each patient effort is captured.

cutaneous monitoring or invasively by arterial, venous, or capillary blood gas analysis. End-tidal $\mathrm{P}_{\mathrm{CO}_{2}}$ monitoring may be attempted, but it is often inaccurate secondary to dilution from the high flow of gas from the delivery device. $\mathrm{CO}_{2}$ targets are disease-specific and should reflect a compensated acid/base status. Other observations related to the work of breathing and the level of consciousness can also provide valuable clinical indicators of the overall oxygenation and ventilation status of the patient.

It is important to have a clear understanding of the patient's baseline clinical status when determining effectiveness of treatment. Many of the tools that are available in the acute care setting are not utilized in the home; therefore, it will be important to educate caregivers about the early recognition of signs and symptoms of respiratory distress or other changes in the clinical status. It is essential that all caregivers be familiar with the complications associated with the noninvasive modalities and the steps necessary to minimize those complications. Chest radiographs can provide useful diagnostic information if clinical symptoms are present and will be a useful tool in evaluating the adequacy of lung inflation during CPAP or NIV. The radiograph may also provide useful information regarding the appropriate EPAP levels to use during NIV.

\section{Clinical Management}

\section{CPAP}

The goal of CPAP is to restore adequate functional residual capacity to correct, reverse, or minimize alveolar collapse. CPAP will effectively reduce the work of breathing as it unloads the work of the inspiratory muscles and allows effective inflation in excess of the opening pressure of the lungs. ${ }^{22}$ Generally, the level of CPAP required to accomplish this goal in infants is usually $5-8 \mathrm{~cm} \mathrm{H}_{2} \mathrm{O}$ but varies with disease process; the level necessary for pediatric patients will be variable based on the indications for use and the severity of disease. Disorders associated with low lung compliance may require CPAP levels in excess of $10 \mathrm{~cm} \mathrm{H}_{2} \mathrm{O}$. CPAP should only be used on patients with an adequate respiratory drive, and pressures should be incrementally increased to achieve the targeted oxygen saturation goal at an $\mathrm{F}_{\mathrm{IO}_{2}}$ of $\leq 0.50-$ 0.60 up to a CPAP level of $10-12 \mathrm{~cm} \mathrm{H}_{2} \mathrm{O}$. CPAP devices are designed to operate under 2 basic principles; one principle is to provide a constant pressure with variable flow, whereas other systems provide constant flow resulting in variable pressure delivery to the patient. Pressure-constant delivery devices are preferred 


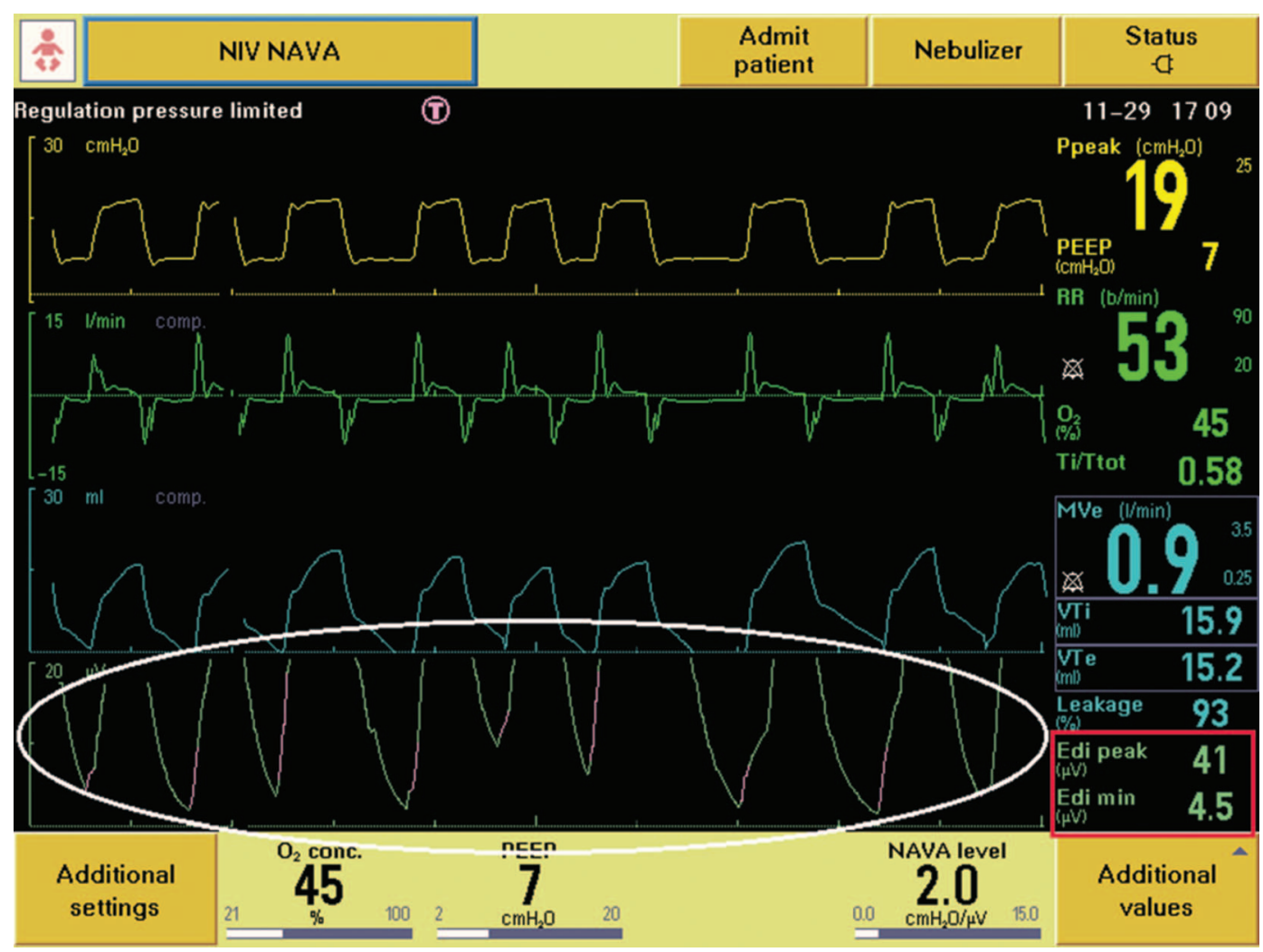

Fig. 5. Noninvasive ventilation-neurally adjusted ventilatory assist (NIV-NAVA) where each patient effort is captured but support is insufficient (maximum electrical signal of the diaphragm [Edi] is 41 , indicating a high inspiratory work of breathing and insufficient NAVA level).

to provide a consistent pressure and prevent alveolar collapse by sustaining lung recruitment. When adequate CPAP levels are achieved, the work of breathing should improve, as evidenced by a decreased breathing frequency, less sternal or intercostal retractions, and improved oxygen saturations.

When CPAP is indicated to treat acute lung disease, $\mathrm{F}_{\mathrm{IO}_{2}}$ and CPAP levels should be weaned as tolerated to maintain acceptable oxygenation levels. Weaning of CPAP support should commence when resolution or resolving disease processes has been identified. Clinical and diagnostic indicators should be evaluated to determine resolution of the disease process and readiness for weaning. In infants, the $\mathrm{F}_{\mathrm{IO}_{2}}$ should be weaned to minimally acceptable levels before weaning CPAP levels. If CPAP is applied intermittently for nocturnal use for the treatment of OSA, the CPAP level is maintained while the $\mathrm{F}_{\mathrm{IO}_{2}}$ is titrated to maintain predetermined saturation levels. Weaning of CPAP may involve intermittent trials of HFNC or standard nasal cannula at increasing intervals (sometimes described as sprints). CPAP can be trialed off when the patient has been stable at a level of $5-6 \mathrm{~cm} \mathrm{H}_{2} \mathrm{O}$ with a $\mathrm{F}_{\mathrm{IO}_{2}}$ of $\leq 0.40$. Patients are often transitioned to HFNC as an intermediate step following CPAP before transitioning to a standard nasal cannula.

\section{NIV}

When NIV is indicated, the clinician must determine the appropriate mode of ventilation to use. The spontaneous mode is a patient-triggered mode that provides an inspiratory pressure assist without a backup frequency. When choosing this mode, the patient must have a good respiratory drive, and the patient must be able to effectively trigger breaths. The timed mode offers a set pressure delivery at a preset mandatory frequency and allows additional patient-triggered breaths as needed. This mode can lead to asynchrony when patient breathing efforts conflict with the set frequency. The spontaneous/timed mode is a patient-triggered mode that provides inspiratory pressure assist with a backup time-based frequency. This mode may offer a combination of patient safety and patient comfort, provided triggering is effective. Each of these modes can be provided by most noninvasive and invasive delivery devices.

Initial settings when implementing NIV support will be patient-specific and require patience on the part of the clinician. It will be important to select the correct patient interface that permits tolerance and maximizes triggering capabilities. If a set breathing frequency is utilized, the frequency will be age-specific and reflect the 


\section{Noninvasive Respiratory Support in INFANTS AND ChildRen}

level of support needed to ensure adequate ventilation. The EPAP setting should provide a resting pressure level that minimizes alveolar collapse and should be increased if evidence of lung volume loss is present. The EPAP setting has a direct relationship with oxygenation and should be titrated based on oxygen saturation. EPAP settings should not exceed 7-8 $\mathrm{cm} \mathrm{H}_{2} \mathrm{O}$ in most infants or $10-12 \mathrm{~cm} \mathrm{H}_{2} \mathrm{O}$ in most pediatric patients, although this is patient-specific and is not an absolute recommendation.

IPAP is applied to the resting expiratory pressure and translates to volume delivery to the patient. IPAP has a linear relationship between pressure and volume. The IPAP setting should be titrated to achieve adequate chest expansion and $\mathrm{CO}_{2}$ removal. Inspiratory time determines the amount of time devoted to inspiration and should be sufficient for breath delivery. Excessively long inspiratory times will be uncomfortable for patients and may increase the work of breathing if patients are forced to exhale against inspiratory flow. Other secondary settings available are dependent on the device used to provide ventilation and may include the trigger sensitivity, the rise time, the breath transition cycle, and a gradual pressure ramp time.

The trigger sensitivity should be set so that the patient can easily initiate a spontaneous or assisted breath without auto-triggering. This can be difficult to achieve secondary to leaks that have a large impact on the triggering mechanism. The rise time reflects the amount of time required to reach the preset pressure during pressure support ventilation or pressure control ventilation and should be set to maximize patient comfort. Patients with restrictive lung disease may prefer a slower rise to improve the distribution of ventilation, whereas patients with increased airway resistance may prefer a more aggressive rise. The cycle time setting determines the transition period from inhalation to exhalation during pressure support ventilation and may be flow- or time-based. The cycle setting should lower the threshold for transition in the presence of large system leaks. The ramp time, if available, will allow gradual increase in the pressure delivery to assist with patient tolerance and comfort. Invasive mechanical ventilation is sometimes indicated to manage patients with respiratory failure; however, there are many complications associated with invasive mechanical ventilation. This has been a catalyst for the use of NIV, which has become increasingly prevalent in infants and children.

System leaks have a much bigger impact in the set-up, management, and weaning strategy and must be considered on an individual patient basis. When patients can trigger the delivery device, the approach is similar to that of invasive ventilator weaning. When significant leaks are present and patients are unable to trigger spontaneous or assisted breaths, spontaneous breaths are usually not supported. In this case, a traditional weaning strategy of in- crementally reducing the mandatory breathing frequency shifts more work to the patient and may substantially increase the work of breathing because spontaneous breaths are not supported. This can be effective for many patients, but the increased work of breathing for patients with limited reserves may result in them not tolerating this strategy. Another approach would be to set the mandatory frequency at a physiological level, based on patient age and disease process, and wean the IPAP until the IPAP and EPAP settings are nearly equal. This approach may offer a more gradual shift of the respiratory muscle work. The optimal weaning strategy requires more research before evidenced-based recommendations can be made. Clinicians should always evaluate the efficiency of current strategies and adjust as needed.

\section{Alternative Approaches to Noninvasive Modalities}

The use of HFNC has become very popular in recent years; however, the data are limited and conflicting. It is important to distinguish the intended goals of therapy when implementing HFNC. ${ }^{23-27}$ The high flow used may be sufficient to produce a CPAP effect, and may flush a portion of the $\mathrm{CO}_{2}$ contained within the anatomical dead space. The definition of high flow varies with age of the patient and is not universal. Flows $\geq 1 \mathrm{~L} / \mathrm{min}$ are generally considered high flow in the neonatal patient, whereas flow ranges for older children are not well established in the literature. Typically, flows $\geq 3 \mathrm{~L} / \mathrm{min}$ meet the criteria for high flow in toddlers, whereas flows $\geq 5 \mathrm{~L} / \mathrm{min}$ are considered high flow in older children. Assumed benefits of HFNC are realized from maximum mucocilliary clearance, reduced inflammatory reactions, inhibition of bronchoconstrictor reflex, reduced airway resistance, and a variable degree of washout of the nasopharyngeal dead space. The evidence for positive pressure delivery with HFNC is mixed and highly variable.

Manley et $\mathrm{a}^{25}$ compared treatment failure in infants within $7 \mathrm{~d}$ of extubation comparing the use of HFNC with CPAP. In this study, $34.2 \%$ of the nasal cannula infants experienced treatment failure, whereas $25.8 \%$ of the CPAP group demonstrated failure. Of the failures, $50 \%$ were successfully treated with CPAP without re-intubation. Based on their predetermined criteria, this led to a conclusion that the use and efficacy of HFNC was not inferior and was therefore similar to that of CPAP as a form of respiratory support for very preterm infants following extubation. The use of HFNC therapy in pediatric patients is popular and often creates conflict of point of care (pediatric ICU vs regular nursing floor). In a pilot study conducted by Mayfield et al, ${ }^{26} 33$ subjects received standard low-flow oxygen while 61 subjects with bronchiolitis were treated with $\mathrm{HFNC}$ at $2 \mathrm{~L} / \mathrm{kg} / \mathrm{min}$ at an $\mathrm{F}_{\mathrm{IO}_{2}}$ sufficient to maintain an oxygen saturation of $94 \%$. Responders and non-responders 


\section{Noninvasive Respiratory Support In INFANTS AND CHILDREN}

to HFNC were identified within $60 \mathrm{~min}$, with nonresponders being 4 times more likely to be admitted to the pediatric ICU than HFNC responders. Pediatric ICU admission was required in 8 of the 61 HFNC group subjects $(13 \%)$ and in 10 of the 33 standard low-flow nasal cannula group subjects (30\%). There were no subject demographic or physiological characteristic differences between the groups. These authors concluded that HFNC responders could be assessed based on heart rate and breathing frequency within the first hour and that responders may be safely cared for on the pediatric wards; they further conclude that this may result in a cost savings by reducing ICU admissions.

In another study conducted by Beggs et al, ${ }^{27}$ comparing standard oxygen therapy with HFNC in 19 bronchiolitis subjects, the authors found some differences in $\mathrm{S}_{\mathrm{pO}_{2}}$ at 8 and $12 \mathrm{~h}$, but no difference was noted at $24 \mathrm{~h}$. There was also no difference in duration of oxygen therapy, LOS, or time to discharge in either group. They did note that HFNC therapy is feasible and well tolerated.

\section{Safety and Complications}

All forms of ventilation require patient safety features related to alarm settings. If the delivery device allows for high tidal volume and high breathing frequency alarms, they should be set at levels that are $20-30 \%$ above baseline delivery. High-pressure alarms should be set at 5-10 $\mathrm{cm} \mathrm{H}_{2} \mathrm{O}$ above IPAP (or PIP) levels. Low-pressure alarms should be set above the EPAP setting but below the IPAP setting. Traditionally, apnea times are set at 10-15 s for infants, 15-20 s for pediatric patients, and 20-30 s for adolescent patients. Backup ventilation settings should reflect full ventilator support. Other safety measures that the clinician should consider are the use of remote monitoring, including video monitoring, central nurse call monitoring for heart rate, saturation, and disconnect, especially if the patient is cared for outside of the ICU setting.

Complications associated with NIV are most often seen in the most fragile patients; they include gastric distention, aspiration, pneumothorax, and pressure ulcerations. Of these, pressure ulcerations are the most preventable. Gastric distention can be minimized by ensuring that all patients receiving NIV have vented gastric tubes in place to circumvent excess air from the stomach. Aspiration precautions involve feeding precautions, close attention to feeding schedules, elevation of the head of the bed, positioning of the patient, careful suctioning procedures to reduce gagging and emesis, and close patient monitoring. Pneumothoraces can be reduced by minimizing pressure delivery while observing changes in volume delivery or chest rise, which may indicate a change in lung compliance. It is important to observe trends in volume delivery and to make appropriate changes in patient and alarm settings to minimize potential harm from positive pressure delivery.

Pressure ulcerations can produce serious complications, and consequences can range from temporary superficial skin discoloration to deep-tissue injury requiring plastic surgery. Pressure ulcerations have been reported in $4-27 \%$ of children. ${ }^{28}$ Pressure ulcerations are classified in stages: Stage 1 is redness at the site and is non-blanchable, state 2 has redness with an opening or blistering at the site of injury (the wound is shallow, and fat is generally not visible), stage 3 has visible fat or slough and is slightly deeper than stage 2 , and stage 4 pressure ulcerations have visible slough and may have exposed bone or muscle.

Visscher et $\mathrm{al}^{29}$ investigated factors contributing to pressure ulcers in 50 subjects. They used color imaging, 3-dimensional surface imaging, and skin hydration measurements to identify early breakdown. They also evaluated 3 interventions to reduce trauma: use of a silicone foam dressing, a water/polyethylene oxide hydrogel dressing, and a flexible water-permeable cloth mask. The interventions were applied upon identification of skin breakdown at any stage. In summary, their findings were that skin breakdown was most severe with the oronasal masks, that the bridge of the nose represented the area of most severe breakdown, and that maintaining normal skin hydration are important interventions for protecting skin tissue integrity.

Humidification is recommended to hydrate secretions and improve patient tolerance when administering CPAP and/or NIV; however, it presents a clinical dilemma related to potential skin breakdown and pressure ulcerations. High humidity has been linked to the development of patient interface pressure points and contributes to the development of pressure ulcerations as outlined by Visscher et al. ${ }^{29}$ The incidence of breakdown associated with oronasal masks has been confirmed in a study by Schallom et $\mathrm{al},{ }^{30}$ where 200 subjects were assigned to either an oronasal mask or a total face mask. Findings showed that 16 subjects in the oronasal group had stage 1 breakdown, whereas none were observed in the total face mask group; 4 subjects were noted to have stage 2 breakdown in the oronasal group, with one in the total face mask group; and none had deep-tissue injury in the oronasal group, whereas one had deep-tissue injury in the total face mask group. The authors concluded that total face masks offer a greater distribution of pressure and therefore less severe pressure ulcerations than the oronasal mask.

Skin ulcerations can be minimized by careful evaluation at regular intervals to identify early signs of potential breakdown and liberal policies enabling routine skin care consults when potential injury is identified. 


\section{Noninvasive Respiratory Support In INFANTS AND CHILDREN}

Caregivers should be trained in the stages of skin breakdown, and safety measures to minimize risk should be routinely employed. Safety measures related to the reduction of skin breakdown should include but are not limited to the intermittent alteration of patient interfaces to rotate pressure points, intermittent interface breaks if tolerated by the patient, and routine inspection and cleansing of the face and interface device to minimize rubbing friction.

\section{Summary}

The key determination of successful implementation of noninvasive respiratory support is to change the trajectory of respiratory distress by alleviating respiratory distress and/or improving gas exchange on a lower $\mathrm{F}_{\mathrm{IO}_{2}}$. The first step is to select the most appropriate delivery modality, CPAP, NIV, or HFNC. Once the delivery modality is determined, the careful selection of the patient interface is important. The patient interface must meet the requirements of the delivery strategy and maximize patient tolerance criteria. Tolerance is important because it will be a key factor in adherence, which is essential for successful treatment. Factors that may improve tolerance are the use of mild sedatives or anti-anxiety agents, a comfortable interface, appropriate system leak management, patient-specific settings that meet the oxygenation and ventilatory needs of the patient, and humidification of gas delivery. A clear understanding of the limitations and operations of delivery devices is key. The clinician must match the patient goals with the available interventions, and they must be able to operate the devices effectively to maximize patient benefits. The clinician must also recognize key differences in the operation of various devices to safely set up, control, and manage the patient. It is important to have clear multidisciplinary expectations for the use and limitations of NIV so that clinical goals can be met with minimal risk to the patient.

\section{REFERENCES}

1. DiBlasi R, Courtney SE. Noninvasive respiratory support. In: Goldsmith JP, Karotkin EH, Keszler M, Suresh GK, editors. Assisted ventilation of the neonate, 6th edition. Philadelphia, Pennsylvania: Elsevier; 2003:162-179.

2. Cheifetz IM. Invasive and noninvasive pediatric mechanical ventilation. Respir Care 2003;48(4):442-458; discussion 453-458.

3. Deorari AK, Thukral A. Continuous positive airway pressure. In: Walsh BK, editor. Neonatal and pediatric respiratory care, 4th edition. St Louis, Missouri: Elsevier; 2015:267-286.

4. Teague GW, Thompson-Batt D. Noninvasive mechanical ventilation of the infant and children. In: Walsh BK, editor. Neonatal and pediatric respiratory care, 4th edition. St Louis, Missouri: Elsevier; 2015:287299.

5. Basnet S, Mander G, Andoh J, Klaska H, Verhulst S, Koirala J. Safety, efficacy, and tolerability of early initiation of non-invasive positive pres- sure ventilation in pediatric patients admitted with status asthmaticus: a pilot study. Pediatr Crit Care Med 2012;13(4):393-398.

6. de Miguel-Díez J, Jiménez-García R, Hernńdez-Barrera B, López de Andrés A, Villa-Asensi JR, Plaza V, Carrasco-Garrido P. National trends in hospital admissions for asthma exacerbations among pediatric and young adult population in Spain (2002-2010). Respir Med 2014;108(7):983-991.

7. Ganu SS, Gautam A, Wilkins B, Egan J. Increase in use of noninvasive ventilation for infants with severe bronchiolitis is associated with decline in intubation rates over a decade. Intensive Care Med 2012;38(7):1177-1183.

8. Abadesso C, Nunes P, Silvestre C, Matias E, Loureiro H, Almeida H. Non-invasive ventilation in acute respiratory failure in children. Pediatr Rep 2012;4(2):e16.

9. Marinón-Torres F. Noninvasive ventilation with helium-oxygen in children. J Crit Care 2012;27:220.e1-220.e9.

10. Pediatric Acute Lung Injury Consensus Conference Group. Pediatr Crit Care Med 2015;16(5):428-439.

11. Flight WG, Shaw J, Johnson S, Webb AK, Jones AM, Bentley AM, Bright-Thomas RJ. Long-term non-invasive ventilation in cystic fibrosis: experience over two decades. J Cyst Fibros 2012;11(3): 187-192.

12. Lima CA, Andrade Ade F, Campos SL, Brandão DC, Fregonezi G, Mourato IP. Effects of noninvasive ventilation on treadmill 6-min walk distance and regional chest wall volumes in cystic fibrosis: Randomized controlled trial: Respir Med 2014;108(10):14601468.

13. Fauroux B. Why, when and how to propose noninvasive ventilation in cystic fibrosis? Minerva Anestesiol 2011;77(11):1108-1114.

14. Chan J, Edman JC, Koltai PJ. Obstructive sleep apnea in children. Am Fam Physician 2004;69(5):1147-1154.

15. Piastra M, Antonelli M, Caresta E, Chiaretti A, Polidori G, Conti G. Noninvasive ventilation in childhood acute neuromuscular respiratory failure: a pilot study. Respiration 2006;73(6): 791-798.

16. Gupta P, Kuperstock JE, Hashmi S, Arnolde V, Gossett JM, Prodhan $\mathrm{P}$, et al. Efficacy and predictors of success of noninvasive ventilation for prevention of extubation failure in critically ill children with heart disease. Pediatr Cardiol 2013;34(4):964-977.

17. Bernet V, Hug MI, Frey B. Predictive factors for the success of noninvasive mask ventilation in infants and children with acute respiratory failure. Pediatr Crit Care Med 2005;6(6):660-664.

18. Schibler A, Franklin D. Respiratory support for children in the emergency department. J Paediatr Child Health 2016;52(2):192196.

19. Stein H, Beck J, Dunn M. Non-invasive ventilation with neutrally adjusted ventilator assist in newborns. Semin Fetal Neonatal Med 2016;21(3):154-161.

20. Baudin F, Pouyau R, Cour-Andlauer F, Berthiller J, Robert D, Javouhey E. Neurally adjusted ventilator assist (NAVA) reduces asynchrony during non-invasive ventilation for severe bronchiolitis. Pediatr Pulmonol 2015;50(12):1320-1327.

21. Hawkins SM, Jensen EL, Simon SL, Friedman NR. Correlates of pediatric CPAP adherence. J Clin Sleep Med 2016;12(6):879884.

22. Loh LE, Chan YH, Chan I. Noninvasive ventilation in children: a review. J Pediatr 2007;83(2 Suppl):S91-S99.

23. Cummings JJ, Polin RA, Committee on Fetus and Newborn, American Academy of Pediatrics. Noninvasive respiratory support. Pediatrics 2016;137(1). doi: 10.1542/peds.2015-3758.

24. Walsh BK. Oxygen administration. In: Walsh BK, editor. Neonatal and pediatric respiratory care, 4 th edition. St Louis, Missouri: Elsevier; 2015:156-157. 


\section{NoninVAsive Respiratory SupPort In INFANTS AND CHILDREN}

25. Manley BJ, Owen LS, Doyle LW, Anderson CC, Cartwright DW, Pritchard MA, et al. High-flow nasal cannulae in very preterm infants after extubation. N Engl J Med 2013;369(15):14251433.

26. Mayfield S, Bogossian F, O'Malley L, Schibler A. High-flow nasal cannula oxygen therapy for infants with bronchiolitis: pilot study. J Paediatr Child Health 2014;50(5):373-378.

27. Beggs S, Wong ZH, Kaul S, Ogden KJ, Walters JA. High-flow nasal cannula therapy for infants with bronchiolitis. Cochrane Database Syst Rev 2014;(1):CD009609.
28. Bergquist-Beringer S, Cuddigan J, Davidson J. National Database of Nursing Quality Indicators. Pressure injury training. https://members. nursingquality.org/ndnqipressureulcertraining/. Accessed March 20, 2017.

29. Visscher MO, White CC, Jones JM, Cahill T, Jones DC, Pan BS. Respir Care 2015;60(11):1536-1547.

30. Schallom M, Cracchiolo L, Falker A, Foster J, Hager J, Morehouse $\mathrm{T}$, et al. Pressure ulcer incidence in patients wearing nasal-oral versus full-face noninvasive ventilation masks. Am J Crit Care 2015; 24(4):349-356.

\section{Discussion}

Panitch: Thanks for a great talk, Kathy. I have a comment and question. The comment is when it comes to nomenclature and ventilator therapy, I think NIV parlance causes greater inaccuracies in what we do. You brought that up in terms of how we reference pressures. But when we talk specifically about neonatal NIV, the terms that are used to describe various modes of therapy that we think are synonymous with NIV modes in older children have nothing to do with each other. In fact, there really are not any studies that look at pressure support ventilation (PSV) that is patienttriggered flow-cycled in neonates; the closest comparison is one study that used abdominal motion by respiratory inductance plethysmography for trigger and cycle signals, but the machine is no longer available. So NIV is a very different modality in neonates. SiPAP is sort of bi-level CPAP. I think it would be great if we could standardize the nomenclature so we all know what we're talking about. My question refers to the use of the ICU ventilator versus a machine that's specifically designed to provide noninvasive support. My experience has been that the ICU ventilator is very intolerant of leak even when you use a non-vented mask, and often patients do better when we can convince our colleagues to switch to a machine designed for the purpose of NIV, where the flow meets patient demand better. I would like your opinions.
Fedor: I would agree, we have seen a lot of that. Sometimes we've switched the patient type to accommodate increased flow demands mode from infant to pediatric in order to accommodate those flows. We've done that even in the face of NAVA with total face shields; we've had to increase our patient age input a (infant to peds, or peds to adult depending on the ventilator) so that the additional flow is necessary. I do think that the standalone devices that have leak compensation offer enhanced triggering capabilities and is an important point that you're bringing up. The issue is that, especially when you get into total face masks, the amount of dead space that exists within the mask itself that has to be overcome by the patient still presents a triggering problem. We have overcome a lot of the ICU ventilator issues by incorporating the use of NAVA for better triggering and improved flow initiation and termination. But not everybody has that capability, and you're absolutely right.

Cheifetz: I am going to challenge you. When you presented the pediatric NIV indication slide, I was surprised that ARDS was not on your list. Then, on the next slide, you surprised me even more when ARDS was listed as an exclusion criterion. First a comment, and then a question. My comment is if you review the Pediatric Acute Lung Injury Consensus Conference (PALICC) publications, ${ }^{1,2}$ the definition of ARDS actually includes NIV criteria. Based on the PALICC publications, they are in essence saying NIV could, and poten- tially should, be used in ARDS, at least for mild-to-moderate ARDS. ${ }^{3}$ Now my question is why do you have ARDS as an exclusion criterion for the use of NIV?

Fedor: I should have quantified that for mild/moderate, I agree. I was thinking of exclusion in the case of severe ARDS where you have such low lung compliance that you cannot effectively ventilate noninvasively.

Cheifetz: With that clarification, I agree.

Berlinski: I would like to comment on 2 issues: first that we need to keep in mind that the use of total face mask increases the risk of aspiration. It's a big challenge in choosing the right interface for the patient. Second that the use of NIV and asthma in the emergency department is definitely not ready for primetime. Even if it takes you a couple more hours to get to the same breathing frequency or the same $\mathrm{F}_{\mathrm{IO}_{2}}$, the expense of $\$ 2,500$ or more that the use of a ventilator adds to the care of the patient without a clear benefit in mortality or morbidity does not seem justified. Maybe it could be used in a very select group of patients where it might save them from intubation. But not as a blanket therapy, because I could see this spreading around the emergency departments of the country adding unnecessary cost.

Fedor: Right, I understand. The primary outcome of that study was safety and tolerance, so those were the outcomes they reported in terms of clin- 
ical outcomes. I would agree that blanket use of NIV for asthma patients in the emergency department is probably not something we want to embrace without carefully choosing our patients.

* Myers: Nice job, Kathy. It's interesting as I sit here and reflect, about a decade ago, we had a neonatal/pediatrics Journal Conference ${ }^{4,5}$ where we talked about a lot of technologies and medication that were not cleared by the FDA for kids, that we adapt and use in the hospital setting to make work. And over a decade later, the technology still hasn't been tested, proven, validated, and cleared by the FDA to do so. We know now that as we try to shift costs from that acute care environment to other entities and locations, that becomes even more problematic with using devices and medications outside of that arena. Again, it's a challenge to industry to look at the ability to adapt and get FDA clearance in these areas to address this pediatric gap that we seem to continue to have for the last 10,20, 30 years.

Walsh: I would actually disagree with that mainly because I think we have twice as many devices on the market now as we did a decade ago. As Kathy alluded to, we have more masks now than ever. We have the devices, and many of them go down to $5 \mathrm{~kg}$. Now, they're expensive. Don't get me wrong, they are not the $\$ 1,500$ bilevel machine, but they are available now. It used to be that they were not available and we would do "muzzlePAP," as I used to call it, with a critical care ventilator and slap a mask on and a black strap. So, we have come a long way; I'm just not sure if we are any clearer as to when we should or shouldn't use it. One of the questions I didn't quite get a solid answer to is when should we escalate and intubate someone who's receiving NIV?
Fedor: That's a really tough question; in terms of making that decision, I think that is probably a patient-bypatient decision. I think there are some clear guidelines like when your pressures exceed a certain point. I don't know that the literature out there presents that clear-cut data. I think hospitals have their own criteria for going from NIV to intubation, such as inspiratory pressures of $30 \mathrm{~cm} \mathrm{H}_{2} \mathrm{O}$, or PEEP, or $\mathrm{F}_{\mathrm{IO}_{2}}$ criteria and those kinds of things. That's a future area where I think we need more concrete data in terms of what constitutes failure.

Rehder: There are some data in adults as well as pediatrics that investigate NIV and the time frame in which you should expect to see improvement. Generally, you should see improvement within the first hour or so. I think that's something we really do need to focus on and encourage; if you're not seeing improvement early, then it's time to escalate, because I think that's where many providers get into trouble. There was at least one study in adults that showed increased mortality with NIV, but I think that's exactly what it was, that those patients didn't improve early and they sat on NIV too long prior to escalation of therapy.

Fedor: Probably some of our biggest challenges are some of the neuro developmentally delayed patients who come into our unit. You need to know what the surrogate's wishes are. It's always a tough call when deciding to intubate them when they present with severe respiratory failure and there are no do-not-resuscitate orders. The donot-intubate advance directive also complicates the question of how far to go.

Stokes: You mentioned briefly the negative pressure devices. At St Jude, we have a long history of using continuous negative pressure, and recently I've been interested in the Hayek oscillator that's a much more sophisticated device than the old converted iron lung we used in the late 70s and early 80 s. Unfortunately, it's not widely available, but I wondered whether you've had any experience with that technology. We have had success recently with a neuromuscular patient with respiratory failure and widespread atelectasis, where we were able to transition him back to his home ventilator by using the Hayek oscillator as a bridge.

Fedor: I do not have any personal experience with that; I have some experience with iron lungs and the chest cuirass, but I do not have any personal experience with the oscillator device.

Cheifetz: I want to go back to a couple points you made during your presentation as well as Tim's [Myers] comment. We need to be careful not to get too caught up in FDA clearance when we know that much of what we do in pediatrics and neonatology involves off-label use of products, devices, and medications. Many of the NIV devices and interfaces you mentioned are not FDA-cleared for the indications that we employ in pediatrics; however, many centers are using this approach with good success in smaller and younger patients. I do agree with Tim's comment that we do not have data to definitely support this approach, but we also do not have data to refute its use. Unfortunately, a lot of what we do in pediatrics is based on anecdotal experience, physiology, and extrapolation from data in neonates and adults, but until more definitive data are available, we are somewhat trapped. I just want to raise the point that many centers do employ a broader use of these products than what the FDA has given clearance.

Fedor: I agree; in the hospital setting, we tend to use those devices offlabel more frequently. Where we probably have our biggest challenge is in transitioning these patients home, and the home care companies may or may not want to take on that liability. 
$\dagger$ Kallstrom: How difficult is it to get these kids home and have a successful experience once they're discharged from the hospital? I say that in light of the fact that there aren't a lot of RTs in home care anymore.

Fedor: Yeah, there are not. I also manage our rehab facility, which is a chronic treatment technology-dependent free-standing hospital, and we really have a lot of readmissions from those patients because we are relying on nurses primarily to provide the hands-on care for these patients, and they don't necessarily have the knowledge base that an RT would have. The reimbursement for RTs is so low in that setting that home care companies aren't providing RTs, they're primarily doing setup and education. Getting adherence at home is a problem; one study talked about $50 \%$ adherence, and that's really not very good when you're talking about something that's potentially lifesaving. It is a really difficult question.

Lin: I want to go back to one of Ariel's [Berlinski] comments made earlier about not necessarily deploying NIV early on in asthma patients as a matter of routine. Certainly, I would agree that we shouldn't do it as a matter of routine, but I do think there is a potential role that should be investigated more fully. Early use of NIV to potentially prevent ICU admission, the thought there being that if we can decrease work of breathing (WOB) by providing NIV support and making it easier for them to get that next breath so they spontaneously decrease their frequency, then perhaps then their WOB decreases, and it becomes a salutary cycle where they continue to improve. I haven't looked at the literature recently, but in the 2000s, maybe about 10 years ago, there were some smaller randomized controlled trials based out of emergency departments that demonstrated a positive signal for decreasing incidence of ICU admission if not even hospitalization. I won- der if you have any thoughts about that?

Fedor: I think the big question there is about decreasing ICU admission. We actually would not initiate NIV on our regular pediatric wards. That represents an escalation of care that we would not do in our facility. We might do it in our intermediate care unit, but even that would be rare. I think it ends up being one of those situations where that might be defined by your workflow at your facility.

Lin: I was referring more to NIV initiation in the emergency department setting, not after they've already been hospitalized.

Fedor: I know that in our emergency department, they will frequently initiate NIV pretty commonly. They have a number of devices now; they even have them on battery-powered transport carts. But they are all admitted to the ICU if they've been committed to NIV in the emergency department.

Berlinski: We have different views about where that patient needs to go. In my opinion, the use of NIV treatment in the emergency department is a surrogate of severity, and I hope we all agree that a patient who requires NIV has no other place to go than the ICU. I have safety concerns if patients are treated with NIV in the emergency department and a few hours later are admitted to a regular ward. I think you need to have protocols to decide therapies and disposition. The use of scorebased evaluations is crucial because it allows you to talk the same language between the wards and the pediatric ICU.

Lin: I believe that we agree that the patient who presents to the emergency department who is in severe distress and is in the upper $25 \%$ of whatever your score range is, then that patient absolutely needs to come to the ICU.
Whether they first receive NIV in the emergency department or not is really a matter of hospital policy. For those patients who are in the bottom of your scoring system, who get one treatment of albuterol and do great, then we certainly don't need to be instituting NIV there. But in those patients who are in the middle, where the usual course of emergency department therapy is they get 3 intermittent nebs and they look a little bit better, but somebody recommends a 2-3-h trial of continuous before making the first call to the ICU ... I wonder if that population of patients, if initiated on NIV at the onset of treatement to help facilitate decreasing their WOB would allow them to recover quicker and not turn a 4-h emergency department stay into a $12-\mathrm{h}$ stay. Would that be a potential very narrow selection of the patient population where empiric use of NIV early on is more effective if they don't respond to that first neb as well as you want them to, and would that population of patients be a very narrow indication for NIV initiation for asthma in the emergency department?

Berlinski: The Journal published a study 6 in adults using NIV and aerosols, where the authors looked at intrapulmonary deposition, $\mathrm{FEV}_{1}$, and outcomes. And those who were receiving NIV + the aerosol had the same deposition but better $\mathrm{FEV}_{1}$. I think before going that route, we need a large trial because of the associated cost. We're not talking about adding $\$ 5$ per therapy, but we are talking about at least $\$ 2,500$ to set up the vent for however many moderate-to-severe asthma patients who come into the emergency department. I don't think that an institution can support this practice without clear data. A randomized controlled trial is the only way you can say for sure when this is a cost-effective treatment modality.

Sweet: Would you do that study in the emergency department setting or in patients admitted to the ICU, with 
the goal of determining whether the time window of NIV needed to turn the patient around would be short enough to make doing it in the emergency department practical? If you're going to go down that path, you would design your study to put the patient in the ICU, assess their response receiving NIV, and then ultimately move the NIV down to the emergency department if you really get a clear signal that doing so would shorten emergency department stays and reduce ICU admissions.

Lin: I would agree that the RCT should happen in the ICU environment, but the question then in applying it broadly becomes if everybody thinks you need to come to the ICU in order to get this started, that sort of defeats the purpose of potentially initiating NIV sooner to prevent the ICU admission in the first place. For safety purposes, I think absolutely the initial RCT should be done in a higher level of monitoring environment that has the potential ability to escalate to higher levels of support, whether that be higher levels of NIV or invasive ventilation. There's certainly an educational component. Many of our emergency department colleagues are less experienced with the initiation of NIV in the acute setting; it's just not something they will typically do. They'll either intubate or send them up to the ICU for additional management. I think it's very interesting that the thought that perhaps early initiation of NIV could lead to a more rapid turnaround by just making it easier for them to breathe and all of the associated things - the anxiety, increased breathing frequency-if you could get rid of that, it potentially allows some of these asthma patients to improve. As an aside, over the past 4 years in St Louis, we've seen 7 cases of asthma deaths, which has got to be an epidemic. There were 2 this past week alone. One didn't come out of the emergency department, and the other had brain death and support was removed in the ICU.

Walsh: I think the RCT should be done in the emergency department, if the goal is to buy time for them because they are fatiguing. The standard practice is NIV use in the ICU if they are fatiguing. In other words, we anticipate they will be intubated if we are not careful, and so we proactively use it. I'm wondering if we can head off fatigue like you're saying if we are proactive in the emergency department. If we anticipate they're fatiguing and are in that moderate-to-severe category, then start it. You're really buying time for steroids and those types of things to kick in, and you're looking for 6-8 $\mathrm{h}$ in those extreme patients. Could you do it and save an ICU admission?

Fedor: I would say you would also have to include upon admission because so many of our admitted patients come from direct admits to the ICU from outside hospitals if you work in an academic setting.

Kuch: I think it's interesting regarding the emergency department and where you would conduct this RCT. A couple things. Brian [Walsh], you mentioned that 6-8 $\mathrm{h}$ and trying to keep them in the emergency room and not admitted to the ICU. I think it becomes more of a challenge unless you decide to do it in an observation unit, as throughput is a big goal right now-to get them out and get them through the emergency department. In addition, it begs the question, if you start someone on NIV because they're moderately fatigued and starting to show some signs, a little bit hypoxic, maybe creeping up $\mathrm{CO}_{2}$ where are they going to end up anyway? I think the default would be admitting them to the ICU even if you capture that; I think there's a sense of at least a day in the ICU either way. That's a hard call to make.
Walsh: No, but the outcome would be that it didn't help, and it would be a negative study. That's what I'm saying, if you can-early intervention is what we're talking about, if you can intervene early-keep them from going to the ICU, then it's a worthy trial. If not, like Ariel is saying, there is no evidence to say whether it's the right thing to do because it adds to cost. So, if you still go to the ICU because you got started on NIV, you just added to the cost and not necessarily taken away.

Kuch: I agree, I feel that finding that patient population might be a very small window where you might be able to save them from the ICU versus going to the ICU either way.

Sweet: I'm stirring the pot here, but my idea was to adjust the current standard of care to then retrospectively identify which patients have a rapid turnaround and might not have needed to go to the ICU. You might be able to retrospectively get some data from your critical care units to clarify that, but to justify an RCT and start in the emergency department with issues of education and practice change may be challenging. It might be easier to get buy-in if you set forth the idea that we move somebody quickly, get them started on NIV quickly, and then identify which patient population subset actually got better quickly and wouldn't ultimately need to be in the ICU.

Kuch: My point is that the neededto-treat number might need to be very large to see that, if that makes sense.

Panitch: I would say that in my institution, currently our pulmonary floor takes care of some children who require NIV and who are very sick. For instance, we admit children with asthma who receive magnesium in the emergency department and are receiving continuous nebulized albuterol, and some of my colleagues wonder why we do that and say, "there is 
anICU very close by; why don't we put this patient where he or she belongs?" So, as we push the envelope in terms of what we do, I think there's nothing wrong with increased observation briefly. The trick is once those sick patients start to get better, can you get them back out of the ICU and into a less expensive, less restrictive environment? But initially, I think the caregivers all might be more appreciative of that ICU environment.

Walsh: I want to go back to Tom's [Kallstrom] comment because some of

\footnotetext{
* Timothy R Myers MBA RRT-NPS FAARC, invited discussant. Mr Myers is the Chief Business Officer, American Association for Respiratory Care.

$\dagger$ Thomas J Kallstrom RRT MBA FAARC, invited discussant. Mr Kallstrom is the Executive
}

the people sitting around this table actually do this. A lot of times hospitals now are providing RTs at their own cost just to try and take better care of these kids. I think it's admirable, I wished everyone did it, it's one way to try and get these medically complex kids from the ICU or hospital setting to home, and we're trying to bridge that gap by paying for it ourselves because we sadly don't get reimbursed.

\section{REFERENCES}

1. Pediatric Acute Lung Injury Consensus Conference Group. Pediatric acute respiratory distress syndrome: consensus recommendations from the Pediatric Acute Lung Injury Consensus Conference. Pediatr Crit Care Med 2015;16(5):428-439.

Director, American Association for Respiratory Care.
2. Khemani RG, Smith LS, Zimmerman JJ, Erickson S, Pediatric Acute Lung Injury Consensus Conference Group. Pediatric acute respiratory distress syndrome: definition, incidence, and epidemiology: proceedings from the Pediatric Acute Lung Injury Consensus Conference. Pediatr Crit Care Med 2015;16(5 Suppl 1):S23-S40.

3. Essouri S, Carroll C, Pediatric Acute Lung Injury Consensus Conference Group. Noninvasive support and ventilation for pediatric acute respiratory distress syndrome: proceedings from the Pediatric Acute Lung Injury Consensus Conference. Pediatr Crit Care Med 2015;16(5 Suppl 1):S102-S110.

4. Current trends in neonatal and pediatric respiratory care. Part 1. Respir Care 2003; 48(3):192-295

5. Current trends in neonatal and pediatric respiratory care. Part 2. Respir Care 2003;48(4):352-464.

6. Galindo-Filho VC, Brandão DC, Ferreira Rde C, Menezes MJ, Almeida-Filho P, Parreira VF, et al. Noninvasive ventilation coupled with nebulization during asthma crises: a randomized controlled trial. Respir Care 2013;58(2):241-249.

This article is approved for Continuing Respiratory Care Education credit. For information and to obtain your CRCE

(free to AARC members) visit

www.rcjournal.com

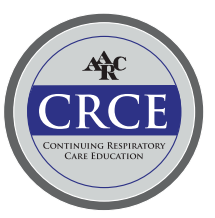

